\title{
Determination of the Anomeric Configuration of Glycosyl Esters of Nucleoside Pyrophosphates and Polyisoprenyl Phosphates by Fast-Atom Bombardment Tandem Mass Spectrometry
}

\author{
Beata A. Wolucka and Edmond de Hoffmann \\ Department of Chemstry, University of Louvam, Louvam-la-Neuve, Belgium \\ Jeffrey S. Rush and Charles J. Waechter \\ Department of Biochemistry, University of Kentucky, College of Medicine, Lexington, Kentucky 40536, USA
}

\begin{abstract}
Collision-induced dissociation of the deprotonated molecules of glycosyl esters of nucleoside pyrophosphates and polyisoprenyl (dolichyl and polyprenyl) phosphates results in distinct fragmentation patterns that depend on cis-trans configuration of the phosphodiester and $2^{\prime \prime}$ (or 2', respectively)-hydroxyl groups of the glycosyl residue. At the collision-offset voltage of $0.5 \mathrm{~V}$, sugar nucleotides with cis configuration produce only one very abundant fragment of nucleoside monophosphate, whereas compounds with trans configuration give weak signals for nucleoside di- and mono-phosphates and their dehydration products. These fragmentation patterns are largely preserved at higher collision energy, with the exception that, for sugar nucleotides with trans configuration, the characteristic signals are much more abundant and a novel diagnostic fragment of [ribosyl(deoxyribosyl)-5'- $\left.\mathrm{P}_{2} \mathrm{O}_{5}-\mathrm{H}\right]^{-}$is generated. In the case of polyisoprenyl-P-sugars, polyisoprenyl phosphate ion is the only fragment observed for compounds with trans configuration, whereas in compounds with cis configuration, this ion is accompanied by another abundant fragment, which is derived from the cleavage across the sugar ring and corresponds to Ipolyisoprenyl- $\left.\mathrm{PO}_{4}-\left(\mathrm{C}_{2} \mathrm{H}_{3} \mathrm{O}\right)\right\rfloor^{-}$. The relative intensity ratio of the latter ion to the [polyisoprenyl- $\left.\mathrm{HPO}_{4}\right]^{-}$ion is close to 1 for compounds with cis configuration, but it is only about 0.01 for compounds with trans configuration. This ratio may serve, therefore, as a diagnostic value for determination of the anomeric configuration of glycosyl esters of polyisoprenyl phosphates. It is proposed that the observed differences in fragmentation patterns of cis-trans sugar nucleotides and polyisoprenyl-P-sugars could be explained in terms of kinetic stereoelectronic effect, and a speculative mechanism of fragmentation of compounds with trans configuration is presented. For compounds with cis configuration, formation of a hydrogen bond between the $C-2^{\prime \prime}\left(2^{\prime}\right)$ hydroxyl and the phosphate group could play a crucial role in directing the specific fragmentation reactions. Consequently, the described empirical rules would hold only for compounds that have a free $2^{\prime \prime}\left(2^{\prime}\right)$-hydroxyl group and no alternative charge location. Owing to its simplicity, sensitivity, and tolerance of impurities, fast-atom bombardment-tandem mass spectrometry represents a suitable method for determination of the anomeric linkage of glycosyl esters of nucleoside pyrophosphates and polyisoprenyl phosphates if the absolute configuration of glycosyl residue is known and the compound fulfills the above-mentioned requirements. (I Am Soc Mass Spectrom 1996, 7, 541-549)
\end{abstract}

$\mathrm{I}$ $\mathrm{n}$ eukaryotes and prokaryotes, lipid-linked saccharides and sugar nucleotides function as "activated" glycosyl donors in the biosynthesis of various $N$ - and O-linked oligosaccharides of glycoproteins, cell-envelope and extracellular polysaccharides, and

Address reprint requests and correspondence to Professor Beata Wolucka, Department of Chemistry, University of Louvain, Place Louis Pasteur 1/1B, B-1348 Louvain-la-Neuve, Belgium. glycosylphosphatidylinositol anchors [1-3]. Sugar nucleotides usually exist as glycosyl esters of nucleoside$5^{\prime}$ mono- and pyrophosphates. Lipophilic glycosyl donors are found as the glycosyl esters of polyisoprenyl mono- and pyro-phosphates. The eukaryotic glycosyl carrier lipids are distinguished from the prokaryotic intermediates by the presence of a saturated $\alpha$-isoprene unit in the polyisoprenyl (dolichyl) moiety. The dolichyl units are also generally longer 
$\left(C_{90-100}\right)$ than bacterial carrier lipids, the most common of which is undecaprenol $\left(\mathrm{C}_{55}\right)$.

Since the discovery by Park and Johnson [4] of uridine diphospho- $N$-acetylmuramyl-pentapeptide- a key intermediate in the assembly of the cell-wall peptidoglycan in bacteria-an impressive number of sugar nucleotides have been isolated and synthesized [5-7]. These sugar nucleotides include several recently discovered nucleotide derivatives [8-12]. On the contrary, there are only a few examples of the isolation of chemical amounts of polyisoprenyl-P-(P)-sugars described in the literature [13-14], and most of the structural information on these glycolipids is based on the chemical properties of intermediates that have been radiolabeled during in vivo and in vitro experiments (for review see $[7,15,16]$ ).

The most common function of activated carbohydrates is to serve as direct donors of sugar moieties for the biosynthesis of glycoconjugates. However many of the activated carbohydrates undergo further conversions and act as intermediates for the biosynthesis of new types of activated sugars. I'his processing may occur either at the level of the sugar nucleotide, which thus results in the formation of "secondary" sugar nucleotides [7], or at the level of the lipid-linked sugar. This processing may involve different modifications of the glycosyl residue, such as substitutions with, for example, glycosyl, amino-acid, pyruvate, or acetyl groups, epimerizations, oxidation, and dehydrationreduction. Another function of the activated carbohydrates is the regulation of the glycoconjugate biosynthesis. For example, in the biosynthesis of $N$-linked oligosaccharides, mannosyl-P-dolichol (Dol-P-Man) was shown to activate UDP-GlcNAc:dolichyl phosphate $N$-acetylglucosamine 1-phosphate transferase (GPT 1) [17], and some secondary sugar nucleotides are known to inhibit specifically the biosynthesis of their sugar nucleotide precursors [5].

Enzymes that employ sugar nucleotides or lipidlinked sugars as substrates are highly stereospecific to only one anomeric form of the substrate [18-20]. Moreover, these enzymes also recognize the anomeric configuration of their lipid-linked sugar or sugar-nucleotide effectors, as was shown for GPT 1 and Dol-P-Man [21]. Thus, knowledge of the anomeric configuration of glycosyl esters of nucleotides and polyisoprenyl phosphates is important for our understanding of the mechanism of glycosyl transfer reactions and also in the preparation of substrates and analogs for specific enzymes [22].

Until now, the anomeric configuration of sugar nucleotides and polyisoprenyl-P-sugars usually was determined either by nondestructive physicochemical melhods, such as NMR and optical rotation measurements, or by different hydrolytic treatments, which include alkaline (and acid) hydrolysis or enzymatic cleavage with specific exoglycosidases and pyrophosphatases, followed by a comparison of the obtained degradation products with authentic sugar and glycosyl phosphate standards $[5,11,23,24]$. All these methods, however, require relatively large quantities of a highly purified sample, which represents a serious limitation because these compounds are very labile and present in only small amounts in living organisms. For methods based on hydrolytic and enzymatic treatments, the problem can be overcome if radiolabeled samples of high purity are available. However, in the case of derivatives that contain unusual glycosyl residues, specific exoglycosidases or appropriate sugar phosphate standards are often lacking, which renders this approach of little help.

Fast-atom bombardment-tandem mass spectrometry (FAB-MS/MS) was applied to the analysis of nucleotides [25-27], sugar nucleotides [8-10, 28], and polyprenyl-P-sugars $[14,29]$ and proved to be a sensitive method to obtain information about the molecular mass, the identity of glycosyl and nucleoside or lipid moieties, and the presence of covalent modifications. The issue of a possible application of the FAB-MS/MS technique to anomeric linkage determination has not emerged from these studies, although the use of collision-induced dissociation to distinguish anomeric and positional isomers of some other sugar derivatives (such as C-glycosides [30], sulfates [31], and unusual nucleosides [32, 33]) was reported. Another, more chemical approach for assignment of the anomeric configuration in oligosaccharides relies on the difference in rates of chromium trioxide oxidation of $\alpha$ - and $\beta$-linked residues in acetylated oligosaccharides and fast-atom bombardment-mass spectrometry (FAB-MS) analysis of the obtained products [34]. This method suffers, however, from different interferences [34].

In a recent communication [35], we demonstrated that very low energy collision-induced dissociation of the deprotonated molecules of glycosyl esters of nucleoside pyrophosphates results in distinct fragmentation patterns that depend on the cis-trans configuration of the phosphodiester and 2 -hydroxyl groups of the glycosyl residue. Consequently, it was shown that the FAB-MS/MS technique can be used for the determination of anomeric configuration of sugar nucleotides provided the absolute configuration of the glycosyl residue is known and the sugar nucleotide has a free 2 -hydroxyl group and no alternative charge location.

The present study further develops these preliminary observations. In particular, we describe here the fragmentations of glycosyl esters of nucleoside pyrophosphates at higher collision energy and also demonstrate the use of fast-atom bombardmenttandem mass spectrometry for the configurational analysis of another group of phosphorylated sugar derivatives, that is, glycosyl-monophospho-dolichols and glycosyl-monophospho-polyprenols. A possible explanation of the differential behavior of anomeric forms of phosphorylated sugar derivatives in tandem mass spectrometry is proposed. 


\section{Experimental}

\section{Chemicals}

All the glycosyl esters of nucleoside pyrophosphates were obtained from Sigma Chemical Co. (St. Louis, MO). Citronellol and undecaprenol were chemically phosphorylated and purified as described earlier [18], and the corresponding $\alpha$ - and $\beta$-mannopyranosyl-Ppolyisoprenols were synthesized chemically and enzymatically, respectively. The details of the chemical and enzymatic syntheses and the isolation and structural characterization of the mannolipids have been described elsewhere [18].

\section{Mass Spectrometry}

Fast-atom bombardment-mass spectrometry was performed on a Finnigan-MAT (San Jose, CA) TSQ 70 triple quadrupole mass spectrometer with an Ion Tech (Middlesex, UK) FAB gun operated at $7 \mathrm{keV}$ and $1 \mathrm{~mA}$ with xenon as the gas. In the tandem mass spectrometry experiments, the pressure of the target gas (xenon) was 0.6 mtorr. Sodium salts of sugar nucleotides were dissolved in water to a concentration of $10 \mathrm{mg} / \mathrm{mL}$, and $0.5 \mu \mathrm{L}$ of the solution was applied to a glycerol matrix. For the analysis of lipid derivatives, $1 \mu \mathrm{L}$ of a $10-\mathrm{mg} / \mathrm{mL}$ solution of glycosyl-P-polyisoprenol in a chloroform-methanol $(2: 1)$ mixture was applied to a thioglycerol matrix.

\section{Results and Discussion}

In our previous work [35], we showed that, at the collision-offset voltage of $0.5 \mathrm{~V}$, deprotonated molecules of sugar nucleotides give very few, although characteristic, fragments that depend on the cis-trans configuration of the phosphodiester and 2"hydroxyl groups of the glycosyl residue. As summarized in Table 1, sugar nucleotides with cis configuration, as in the case of uridine $5^{\prime}(\alpha-D-g l u c o p y r a n o s y l$ pyrophosphate) (UDP- $\alpha$-D-glucose: Figure 1c) produce, in tandem mass spectrometry, only one very abundant fragment that corresponds to nucleoside monophosphate $\left[\mathrm{NMP}-\mathrm{H}^{-}\right.$. On the contrary, the collisioninduced dissociation spectra of sugar nucleotides with trans configuration, for example, of uridine 5' $(\alpha-D-$ mannopyranosyl pyrophosphate) (UDP'- $\alpha$-D-mannose; Figure 1a), show the presence of weak signals of the corresponding nucleoside $\mathrm{di}$ - and monophosphates $[\mathrm{NDP}-\mathrm{H}]^{-}$and $[\mathrm{NMP}-\mathrm{H}]^{-}$and their dehydration products [NDP $\left.\mathrm{H}_{2} \mathrm{O} \quad \mathrm{H}\right]^{-}$and [NMP $-\mathrm{H}_{2} \mathrm{O}-$ $\mathrm{H}^{-}$, respectively (Table 1 ). Examination of sugar nucleotides different with respect to the glycosyl residue (i.e., isomers of hexopyranoses, a pentopyranose, and a $6^{\prime \prime}$-deoxyhexopyranose) and/or the base demonstrated that hydroxyl groups other than the $2^{\prime \prime}-\mathrm{OH}$ of the glycosyl residue as well as the nature of the base have only little effect on the behavior of a compound in tandem mass spectrometry (Table 1). However, a substitution at the $\mathrm{C}-2^{\prime \prime}$ position, as in the case of uridine 5 '- $(\alpha-N$-acetyl-2-amino, 2-deoxy-D-glucopyranosyl pyrophosphate), or the presence of a novel easily ionizable functional group within the sugar moiety (as in UDP- $\alpha$-D-glucuronic acid) result in a dramatic change of the fragmentation pattern (Table 1), which thus points to the key rolc of the phosphate and C-2" hydroxyl groups of the glycosyl residue in the collision-induced dissociation of sugar nucleotides.

Tandem Mass Spectrometry of the $\left[\mathrm{M}-\mathrm{H}^{-}\right.$Ion of Sugar Nucleotides at Higher Collision Energy

At the collision-offset voltage of $15 \mathrm{~V}$, tandem mass spectra of the deprotonated molecules of sugar nucleotides show the presence of intense signals for all the characteristic fragments observed at low (0.5-eV) collision energy (Figure 1 and Table 1), but also for some new fragments. Thus, for example, the $[\mathrm{M}-\mathrm{H}]^{-}$ deprotonated molecule of UDP- $\alpha$-D-mannose at $\mathrm{m} / \mathrm{z}$ 565 (Figure 1b) produces abundant fragments that correspond to $[\mathrm{UDP}-\mathrm{H}]^{-}, \quad\left[\mathrm{UDP}-\mathrm{H}_{2} \mathrm{O}-\mathrm{H}\right]^{-}$, $[\mathrm{UMP}-\mathrm{H}]^{-}$, and $\left[\mathrm{UMMP}-\mathrm{H}_{2} \mathrm{O}-\mathrm{H}\right]^{-}$at $m / z 403$, 385,323 , and 305 , respectively, whereas in a tandem mass spectrum of UDP- $\alpha$-D-glucose, UMP (at $m / z$ 323 ) is the only abundant fragment observed (Figure 1d). The product ion spectrum of the $[\mathrm{M}-\mathrm{H}]^{-}$ion of UDP- $\alpha$-D-mannose displays, in addition, a new very abundant ion at $m / z 273$ that is derived from the loss of uracil and mannosyl residue of the UDP-mannose molecule and corresponds to [ribosyl-5'- $\left.\mathrm{P}_{2} \mathrm{O}_{5}-\mathrm{H}\right]^{-}$. In agreement with such assignment, this ion is shifted by 16 mass units (at $m / z 257$ ) in the case of TDP-glucose- a deoxyribose-containing sugar nucleotide (Table 1). As shown in Table 1, the $\mathrm{m} / \mathrm{z} 273$ ion represents one of the major fragments in tandem mass spectra of sugar nucleotides with trans configuration of the phosphodiester and 2"-hydroxyl groups and is much less abundant in the case of compounds with cis configuration.

Other less abundant ions, such as $\left[\mathrm{HP}_{2} \mathrm{O}_{6}\right]^{-}$(at $m / z$ 159), glycosyl-1" $-\mathrm{PO}_{3}$, and glycosyl-1" $-\mathrm{P}_{2} \mathrm{O}_{6}$ (at $\mathrm{m} / \mathrm{z}$ 241, 225, 211 and $m / z$ 321, 305, 291 for hexosyl, 6"-deoxyhexosyl and pentosyl esters of nucleoside pyrophosphates, respectively) are observed in tandem mass spectra of the deprotonated molecules of sugar nucleotides (Table 1). However, these fragments are not diagnostic for determination of the anomeric configuration of glycosyl esters of nucleoside pyrophosphates.

The presence of fragments derived from the loss of the whole molecule of phosphoric acid $\left(-\mathrm{H}_{3} \mathrm{PO}_{4}\right)$ in the product ion spectra of sugar nucleotides (especially that of UDP- $\alpha$-D-mannose and TDP- $\alpha$-D-glucose; Table 1 ), but also of a more common fragment at $\mathrm{m} / z 211$ 


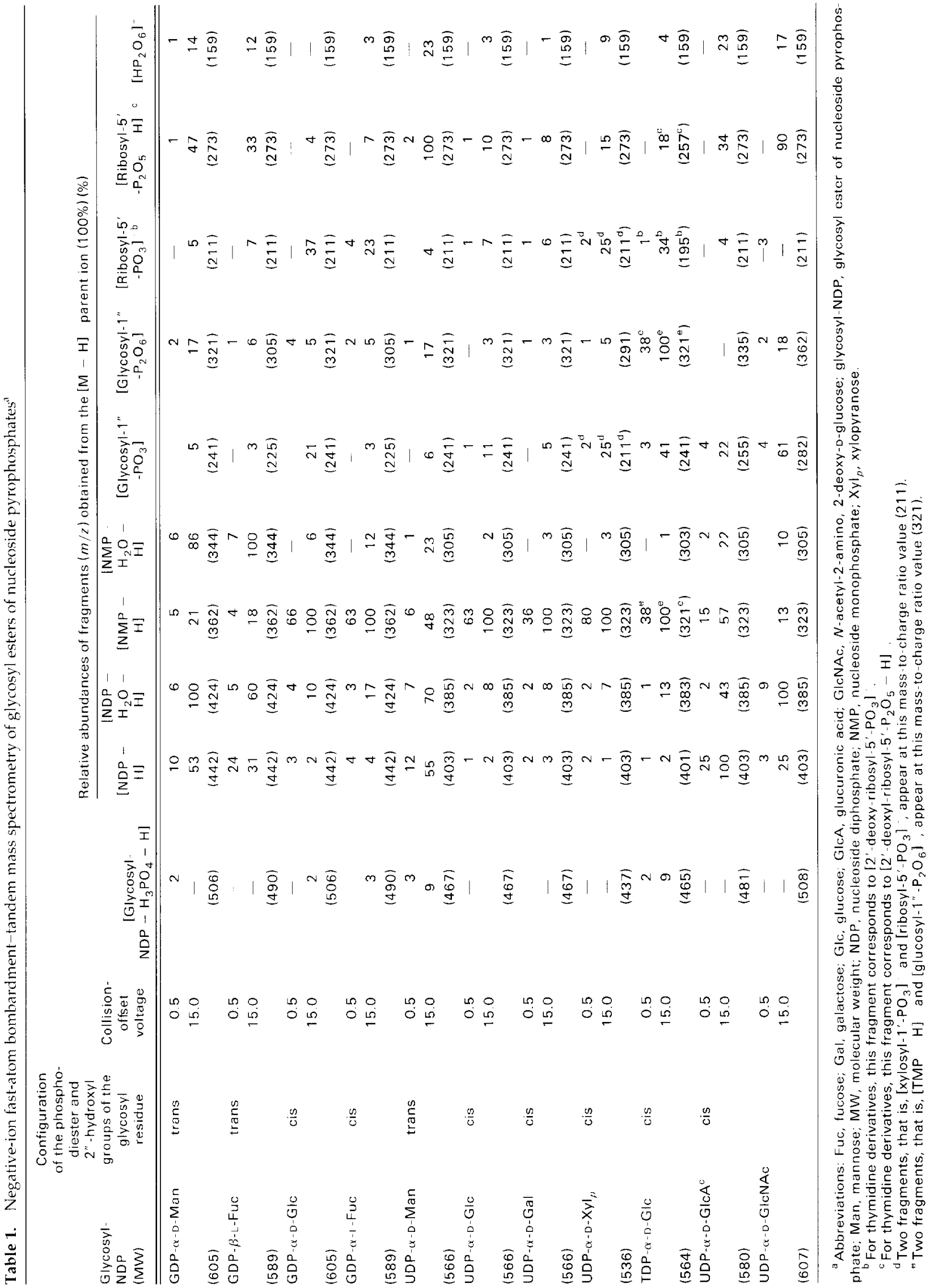


(a)

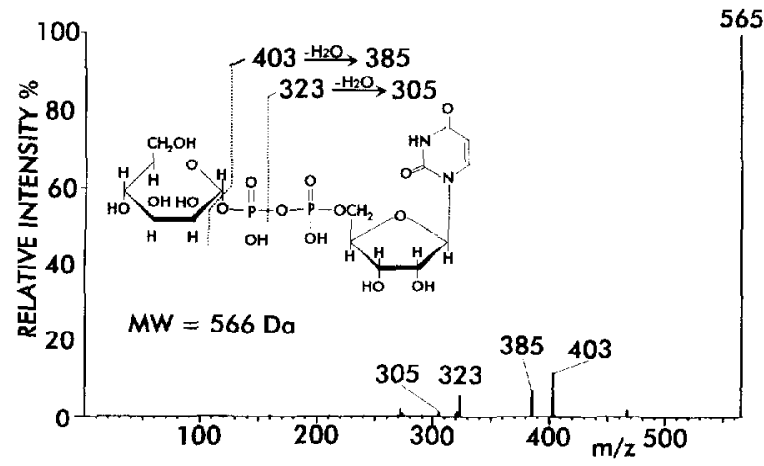

(c)

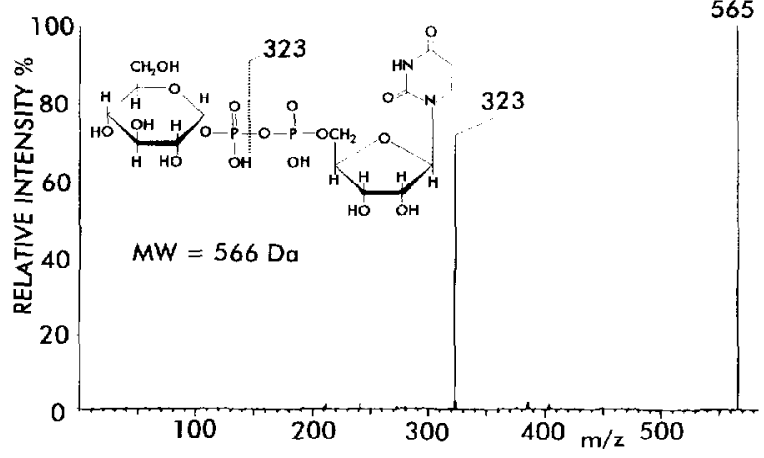

(b)

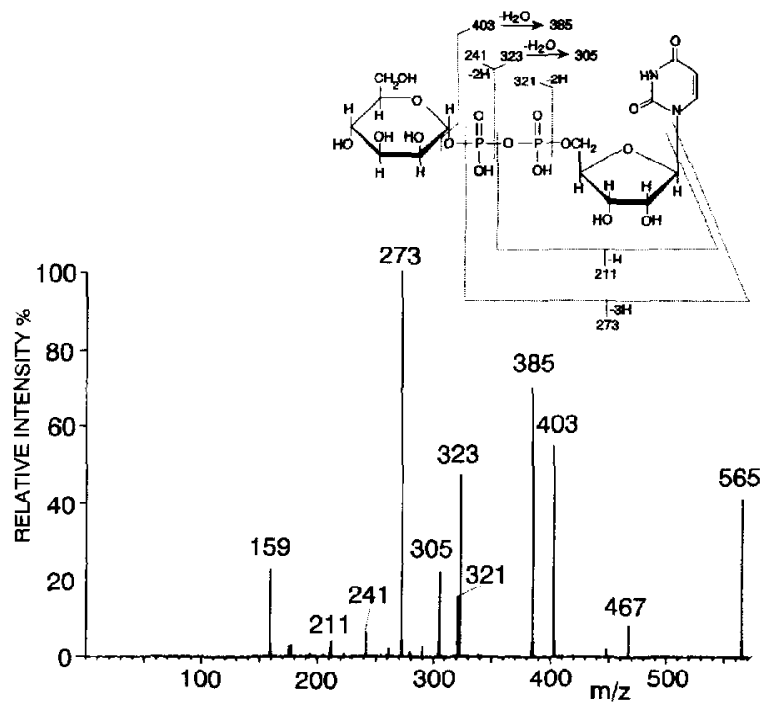

(d)

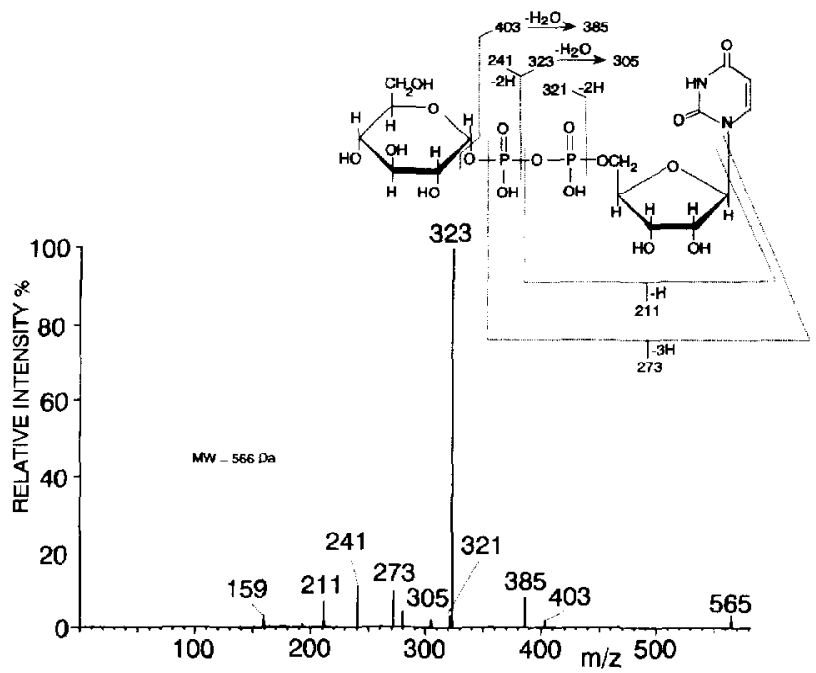

Figure 1. The product ion spectrum of the $[\mathrm{M}-\mathrm{H}]^{-}$deprotonated molecule of uridine $5^{\prime}(\alpha-\mathrm{D})$-mannopyranosyl pyrophosphate) (UDP- $\left.\left.\alpha-1\right)-M a n\right)\left[(\mathbf{a})\right.$ and (b)] and uridine $5^{\prime}(\alpha-\mathrm{D}-\mathrm{gluco}-$ pyranosyl pyrophosphate) (UDP- $\alpha-\mathrm{D}-\mathrm{Glc})[(\mathrm{c})$ and $(\mathrm{d})]$. The collision-offset voltage was $0.5 \mathrm{~V}[(\mathbf{a})$ and (c)] and $15 \vee[($ b) and (d)]. (a) and (c) are reproduced from our previous report [35].

(or $m / z$ 195), which can be attributed to [ribosyl(or deoxyribosyl)-5'- $\left.\mathrm{PO}_{3}\right]^{-}$together with the previously described ion at $m / z 273$ (or $m / z 257$ for deoxyribose-containing derivatives), points to the occurrence of profound molecular rearrangements before or during collision-induced dissociation of the deprotonated molecules of sugar nucleotides. Analysis of precursor ions of the $\left[\text { ribosyl-5' }-\mathrm{PO}_{3}\right]^{-}$fragment $(m / z$ 211) derived from the deprotonated molecule of UDP- $\alpha-\mathrm{D}-$ mannose revealed the presence of [UMP $-\mathrm{H}]^{-}$, [UDP $-\mathrm{H}]^{-}$, and $[\mathrm{M}-\mathrm{H}]^{-}$among precursor ions (not shown). Significantly, neither [ribosyl-5'- $\mathrm{P}_{2} \mathrm{O}_{5}-\mathrm{H}$ ] (at $m / z$ 273) nor [UDP $-\mathrm{I}_{2} \mathrm{O}-\mathrm{H}$ ] (at $m / z$ 385) could be detected among precursors of the $m / z 211$ ion. Furthermore, the product ion spectra of the [UMP $-\mathrm{H}^{-}$and [UDP $\left.-\mathrm{H}\right]^{-}$fragments present in the FAB spectrum of UDP- $\alpha$-D-mannose clearly displayed an ion at $m / z 211$. On the other hand, a precursor ion spectrum of the $m / z 273$ fragment revealed the presence of [UDP $\left.-\mathrm{H}_{2} \mathrm{O}-\mathrm{H}\right]^{-},[\mathrm{UDP}-\mathrm{H}]^{-}$, and $[\mathrm{M}-$ $\mathrm{H}^{-}$as parents (not shown). These results indicate that [ribosyl(or deoxyribosyl)-5'- $\left.\mathrm{PO}_{3}\right\rceil$ and [ribosyl(or deoxyribosyl)-5'- $\left.\mathrm{P}_{2} \mathrm{O}_{5}-\mathrm{H}\right]^{-}$fragments are generated by independent fragmentation pathways, the elucidation of which obviously requires further investigation.

\section{Tandem Mass Spectrometry of the [M - H] Deprotonated Molecule of Glycosyl Esters of Polyisoprenols}

The group of polyisoprenyl alcohols comprises two distinct classes of compounds: polyprenols, in which all the isoprene units are unsaturated, and dolichols, in which the terminal $\alpha$-isoprene unit that bears the hydroxyl group is saturated [1]. Phosphorylated forms of polyisoprenols are involved in glycoconjugate biosyn- 
thesis; polyprenyl phosphates (typically $\mathrm{C}_{55}$-undecaprenyl derivatives) are characteristic for bacteria, whereas, in eukaryotes, dolichyl phosphates that range in their chain length from $C_{60}$ (in lower eukaryotes) to $\mathrm{C}_{90-100}$ (in higher eukaryotes) are usually found. For our studies, we have chosen a fully unsaturated $\mathrm{C}_{55^{-}}$ undecaprenol and an $\alpha$-saturated $C_{10}$-citronellol as model compounds. $\alpha$ - and $\beta$-anomers of D-mannopyranosyl esters of the corresponding undecaprenyl and citronellyl phosphates have been prepared and analyzed by negalive-ion last-atom bombardmenttandem mass spectrometry.

Figure $2 \mathrm{a}$ and $\mathrm{c}$ shows the product ion spectra of the $[\mathrm{M}-\mathrm{H}]^{-}$deprotonated molecules of the $\alpha$-D-mannopyranosyl esters of citronellyl-P and undecaprenyl-P, respectively. In both cases, the only fragment observed is derived from the loss of the mannosyl residue and corresponds to polyisoprenyl phosphate, that is, [citronellyl- $\left.\mathrm{HPO}_{4}\right]^{-}$at $m / z 235$ (Figure $2 \mathrm{a}$ ) and [undecaprenyl- $\left.\mathrm{HPO}_{4}\right]^{-}$at $m / z 845$ (Figure $2 \mathrm{c}$ ), respectively.
On the contrary, the tandem mass spectra of the $[\mathrm{M}-\mathrm{H}]^{-}$deprotonated molecules of $\beta$-D-mannopyranosyl esters of citronellyl and undecaprenyl phosphates reveal the presence of several abundant ions (Figure $2 b$ and $d$ ). Thus, in addition to the already described [polyisoprenyl- $\left.\mathrm{HPO}_{4}\right]^{-}$fragment, an $[\mathrm{M}-$ $\left.\mathrm{H}_{2} \mathrm{O}-\mathrm{H}\right]$ dehydration ion is observed readily at $m / z 379$ for the citronellyl derivative (Figure $2 b$ ) and at $m / z 989$ for the undecaprenyl derivative (Figure $2 \mathrm{~d})$. Also, a characteristic abundant fragment that results from the cleavage across the sugar ring and corresponds to [polyisoprenyl- $\left.\mathrm{PO}_{4}-\left(\mathrm{C}_{2} \mathrm{H}_{3} \mathrm{O}\right)\right]^{-}$is formed in collision-induced dissociation of the depro tonated molecules of $\beta$-D-mannosyl-P-citronellol and $\beta$-D-mannosyl-P-undecaprenol at $m / z 277$ (Figure 2b) and 887 (Figure $2 \mathrm{~d}$ ), respectively. A similar fragmentation pattern was observed in tandem mass spectrometry of the deprotonated molecule of $\beta$-Darabinofuranosyl-monophospho- $\mathrm{C}_{50}$-decaprenol isolated from mycobacteria [14].

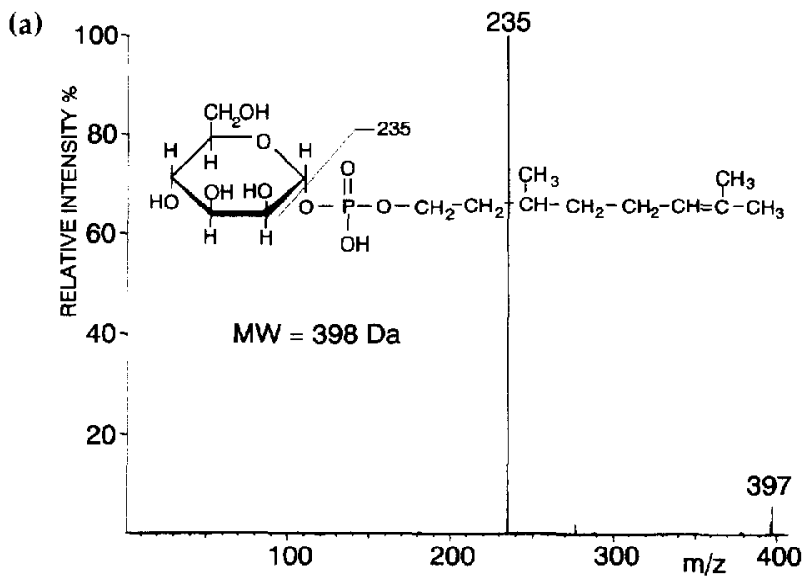

(b)

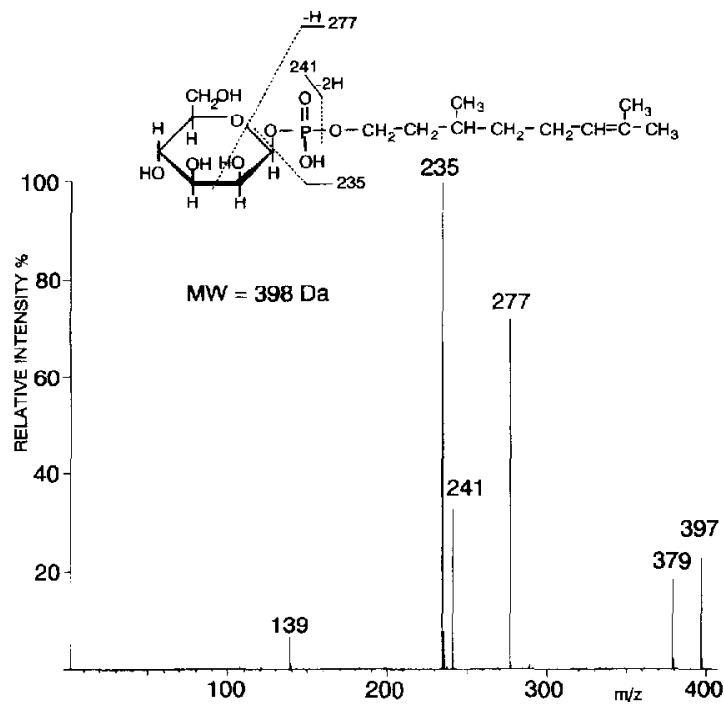

(c)

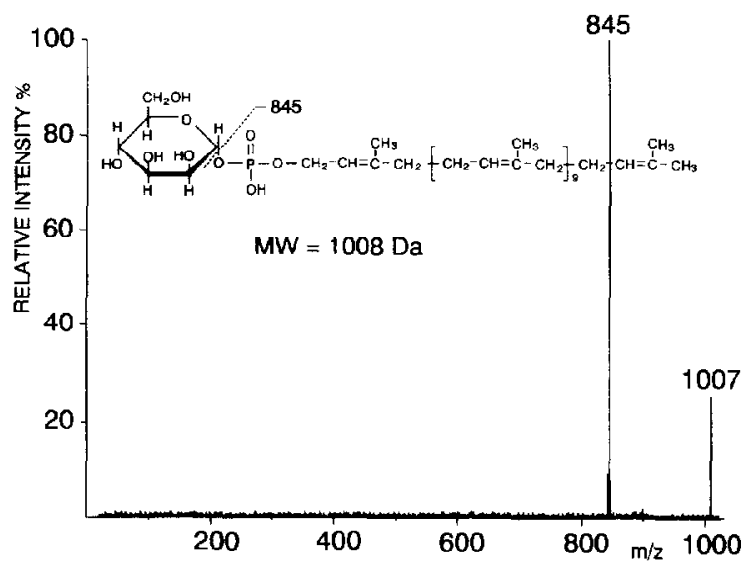

(d)

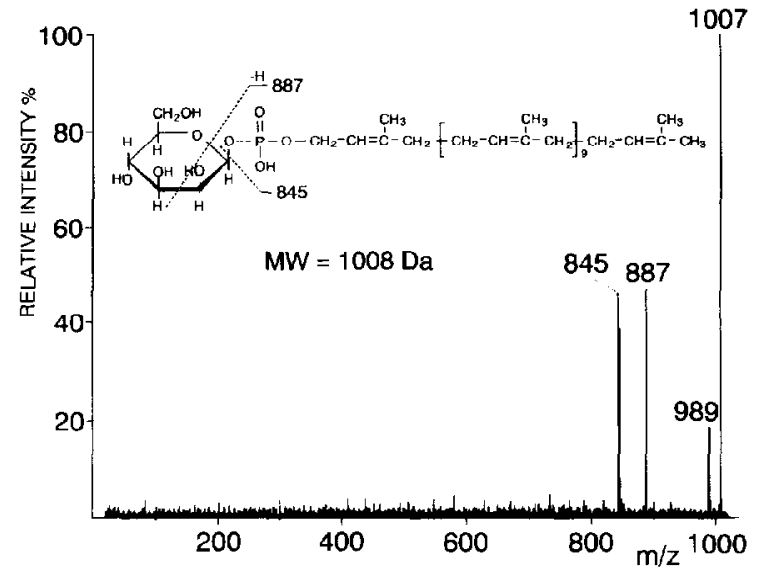

Figure 2. The product ion spectrum of the $[\mathrm{M}-\mathrm{H}]$ deprotonated molecule of (a) $\alpha$-1)-mannopyranosyl-1-monophospho-citronellol, (b) $\beta$-1)-mannopyranosyl-1-monophospho-citronellol, (c) $\alpha$-L-mannopyranosyl-1-monophospho-undecaprenol, and (d) $\beta$-1)-mannopyranosyl-1-monophospho-undecaprenol. The collision-offset voltage was $10 \mathrm{~V}$. 
The product ion spectrum of the $[\mathrm{M}-\mathrm{H}]$ deprotonated molecule of $\beta$-1)-mannopyranosyl-P-citronellol shows the presence of two additional signals at $\mathrm{m} / \mathrm{z}$ 241 and 139 (Figure 2b). The $m / z 241$ ion can be attributed to mannosyl-1'- $\mathrm{PO}_{3}$ ion. This type of fragment (at $m / z 241$ and 211 for a hexosyl and a pentosyl derivative, respectively) also was observed in the product ion spectra of the deprotonated molecules of mannosyl and arabinosyl esters of a partially saturaled $\mathrm{C}_{35}$-octahydroheptaprenyl phosphate isolated from Mycobacterinn smesmatis [29].

Our results clearly demonstrate that the anomeric configuration of 10-mannopyranosy esters of polyisoprenyl phosphates can be determined easily by using fast-atom bombardment-tandem mass spectrometry (Figure 2). The data presented in Table 2 indicate that compounds with cis configuration of the phosphate and 2 '-hydroxyl groups (as in $\beta$-D-mannosyl-P-undecaprenol and the mycobacterial $\beta$-D-arabinofuranosylP-decaprenol) produce, in tandem mass spectrometry, abundant fragments of $\left[\text { polyisoprenyl- } \mathrm{PO}_{4}-\left(\mathrm{C}_{2} \mathrm{H}_{3} \mathrm{O}\right)\right]^{-}$ and [polyisoprenyl- $\left.\mathrm{HPO}_{4}\right]^{--}$, and the ratio of the relative intensities of these two fragments is close to 1 . On the contrary, the deprotonated molecules of glycosyl-P-polyisoprenols with trans configuration of the phosphate moiety and the 2'-hydroxyl group of the glycosyl residue (as in $\alpha$-1)-mannopyranosyl-P-undecaprenol and the mycohacterial $\beta$-D-ribofuranosyl-Pdecaprenol [36]) produce only the [polyisoprenyl$\left.\mathrm{HPO}_{4}\right]$ fragment and, consequently, the ratio of the relative intensities of the [polyisoprenyl- $\mathrm{PO}_{4}$ $\left(\mathrm{C}_{2} \mathrm{H}_{3} \mathrm{O}\right)$ ] ion to the [polyisoprenyl- $\mathrm{HPO}_{4}$ ] ion is close to 0.01 (Table 2).

The presented data point to the crucial role of the phosphate and 2" (2')-hydroxyl groups of the glycosyl moiety in the differential behavior of anomeric forms of glycosyl esters of nucleoside pyrophosphates and polyisoprenyl phosphates during collision-induced dissociation. It is generally accepted that, in a gas phase, molecules tend to be relatively compact, and the stabilization of their tertiary structures is achieved through different forms of "internal solvation," in which hydrogen bonding plays an important role. We propose that formation of a hydrogen bond between the phosphate group and the 2" (2')-hydroxyl group of the glycosyl residue (or possibly of a 1,2-cyclic-phosphate derivative) may be critical and could result in phosphate charge delocalization and in favoring specific fragmentation reactions. Such hydrogen bonding (or cyclization) would not be sterically feasible in furanosyl derivatives with trans configuration of the substituents at $C-1^{\prime \prime}\left(1^{\prime}\right)$ and $C-2^{\prime \prime}\left(2^{\prime}\right)$ nor in pyranosyl residues with axial-axial arrangement of the corresponding groups, as it is likely to be in $\beta$-r)ribofuranosyl- and $\alpha$-D-mannopyranosyl esters, respectively. In agreement with this speculation, the fragmentation patterns of $\alpha$-D-mannopyranosyl esters of nucleotides (Figure $1 \mathrm{a}$ and $\mathrm{b}$ and Table 1 ) and polyisoprenyl phosphates (Figure $2 \mathrm{a}$ and $c$ ) and of $\beta$-Dribofuranosyl-P-decaprenol (Table 2) differ substantially from those recorded for the corresponding compounds with cis configuration of the $C-1^{\prime \prime}\left(1^{\prime}\right)$ and $C$ $2^{\prime \prime}\left(2^{\prime}\right)$ oxygens: $\alpha$-D-glucopyranosyl esters of nucleotides (Figure $\mathrm{Ic}$ and $\mathrm{d}$ and Table 1), $\beta$-D-mannopyranosyl esters of polyisoprenols (Figure $2 b$ and $d$ ), and $\beta$-D-arabinofuranosyl-P-decaprenol (Table 2), respectively. $\Lambda$ s a result, compounds that do not have a free $2^{\prime \prime}\left(2^{\prime}\right)$-hydroxyl group or that contain an alternative charge location would be expected to fragment differently, and this is, indeed, observed for UDP- $\alpha-D-$ GICNAc and UDP- $\alpha$-D-glucuronate (Table 1).

Very little is known about conformations of sugars in a gas phase [37]. It is reasonable to postulate that the gas-phase conformations of many glycosyl residues will be different from those that prevail in aqueous solutions and that the axial disposition of hydroxyl groups of the sugar residue would be preferable. Then, only compounds with trans configuration could adopt a di-axial conformation at $C-1^{\prime \prime}\left(1^{\prime}\right)$ and $C-2^{\prime \prime}\left(2^{\prime}\right)$ with anliperiplanar disposilion of the $\mathrm{O}-1^{\prime \prime}\left(1^{\prime}\right)$ and $\mathrm{O}-2^{\prime \prime}\left(2^{\prime}\right)$ atoms. We speculate that this particular conformation could be essential for the reactivity of trans com-

Table 2. Comparison of the relative abundances of fragments obtained by fast-atom bombardment-tandem mass spectrometry of the $[\mathrm{M}-\mathrm{H}]^{-}$deprotonated molecules of glycosyl esters of polyisoprenyl phosphates"

\begin{tabular}{|c|c|c|c|c|}
\hline \multirow[b]{2}{*}{ Compound } & \multirow{2}{*}{$\begin{array}{l}\text { Configuration of the } \\
\text { phosphodiester and } \\
2^{\prime} \text {-hydroxyl groups } \\
\text { of the glycosyl residue }\end{array}$} & \multicolumn{2}{|c|}{ Relative abundance $(\%)$} & \multirow[b]{2}{*}{ B/A ratio } \\
\hline & & $\begin{array}{c}\mathrm{A} \\
\left.\text { [polyisoprenyl } \mathrm{HPO}_{4}\right]^{-}\end{array}$ & $\begin{array}{c}\mathrm{B} \\
\left.\text { [polyisopreny| } \mathrm{PO}_{4}\left(\mathrm{C}_{2} \mathrm{H}_{3} \mathrm{O}\right)\right]\end{array}$ & \\
\hline$\alpha$-D-Man ${ }_{p}-$ P-citronellol & trans & 100 & 2 & 0.02 \\
\hline$\beta$-D-Man $p$-P-citronellol & $\operatorname{cis}$ & 100 & 12 & 0.12 \\
\hline$\alpha$-D-Man ${ }_{p}$-P-undecaprenol & trans & 100 & 1 & 0.01 \\
\hline$\beta$-U-Man ${ }_{D}$-P-undecaprenol & cis & 46 & 47 & 1.02 \\
\hline$\beta$-D $-A_{1},-P$-decaprenol ${ }^{b}$ & cis & 57 & 67 & 1.18 \\
\hline$\beta$-D-Rib $-\mathrm{P}$-decaprenol & transs & 100 & 6 & 0.06 \\
\hline
\end{tabular}

\footnotetext{
The collision-offset voltage was $10 \mathrm{~V}$. Abbreviations: Ara, arabinofuranosyl; Man , mannopyranosyl; Rib, ribofuranosyl.

"This compound was isolated from Mycobacterium smegmatis and characterized [14]

"This compound was isolated from Mycobacterium smegmatis and characterized [36].
} 
pounds in the gas phase and that the specific fragmentation of trans derivatives represents an example of kinetic stereoelectronic effect. Accordingly, the antiperiplanar orientation of the $\mathrm{O}-1^{\prime \prime}\left(1^{\prime}\right)$ and $\mathrm{O}-2^{\prime \prime}\left(2^{\prime}\right)$ could result in a very fast expulsion of the phosphate group $\left(\mathrm{R}-\mathrm{HPO}_{4}^{-}\right)$in an $\mathrm{S}_{\mathrm{N}}$ 2-like intramolecular reaction due to a nucleophilic attack of the $\left(-2^{\prime \prime}\left(2^{\prime}\right)\right.$ oxygen on the exocyclic $\mathrm{C}-\mathrm{O}$ acetal bond, which could be facilitated by an intramolecular base catalysis, as shown in Scheme I. In Scheme I this reaction is presented as a one-step reaction. However, it may involve several conformational changes of the sugar ring between the proton transfer and the $S_{\Lambda}$ reaction and, consequently, it could be regarded then as a multistep reaction. Also, a simpler mechanistic scheme might be considered if the existence of an oxyanion deprotonated at the $\mathrm{O}$ $2^{\prime \prime}\left(2^{\prime}\right)$ is assumed instead of a phosphate anion. Then the proposed $S_{N}$ 2-like intramolecular reaction would not require a proton transfer via a seven-membered cyclic state. As a result, the only fragment observable in collision-induced dissociation spectra of compounds with trans configuration would be $\left[\mathrm{R}-\mathrm{HPO}_{4}\right]^{-}$. In agreement with this prediction, fragmentation of $\alpha-D-$ mannopyranosyl-containing nucleoside pyrophosphates and polyisoprenyl phosphates (and also of $\beta$ D-ribofuranosyl-P-polyisoprenol) produces [NDP $\mathrm{H}]^{-}$ion (and its decomposition products) and [polyisoprenyl- $\left.\mathrm{HPO}_{4}\right]^{-}$ion, respectively. Similarly, the collision-induced dissociation of silver ion adducts of cis-trans isomers of methyl glycosides that differ only in the relative positions of the $\mathrm{O}-1$ and $\mathrm{O}-2$ atoms seems to undergo a stereochemical control [38]. The above-described mechanism would not be possible for compounds with cis configuration. These compounds would fragment, therefore, via other routes and the hydrogen bonding between the phosphate and $2^{\prime \prime}\left(2^{\prime}\right)$ hydroxyl groups of the glycosyl residue could play an important role in directing these reactions.

\section{Conclusions}

The results described here demonstrate that the anomeric configuration of a glycosyl ester of nucleoside pyrophosphates and polyisoprenyl phosphates of known absolute configuration can be determined by

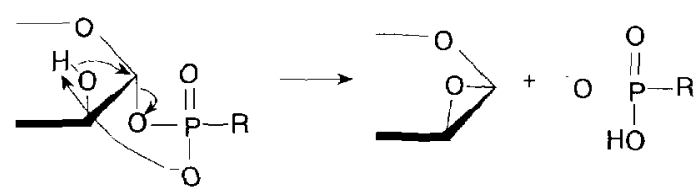

Scheme 1. A speculative mechanism of the fragmentation of glycosyl esters of nucleoside- $5^{\prime}$ pyrophosphates and polyisoprenyl phosphates with trans configuration of the $\mathrm{O}-1^{\prime \prime}\left(1^{\prime}\right)$ and $\mathrm{O}-2^{\prime \prime}\left(2^{\prime}\right)$ atoms; $\mathrm{R}$, represents a nucleoside monophosphate or a polyisoprenyl chain. fast-atom bombardment-tandem mass spectrometry provided the glycosyl residue does not contain an alternative charge location and has a free hydroxyl group at the $C-2^{\prime \prime}\left(2^{\prime}\right)$ position. Then the product ion spectrum of a deprotonated molecule, [M $-\mathrm{H}]$, , shows a characteristic pattern that depends on the cis-trans configuration of the phosphodiester and $2^{\prime \prime}\left(2^{\prime}\right)$-hydroxyl groups of the sugar moiety. For sugar nucleotides with cis orientation of the above-mentioned groups (as in NDP- $\alpha-D-G l c$ ), the diagnostic fragment is a nuclcoside monophosphate [NMP $-\mathrm{H}]^{-}$, and this is the only abundant ion observed. In the case of sugar nucleotides with trans configuration of the phosphodiester and 2"-hydroxyl groups (as in NDP- $\alpha$ D-Man), four major fragments are obtained from the $[\mathrm{M}-\mathrm{H}]^{-}$ion at very low collision energy, namely, the nucleoside diphosphate [NDP $-\mathrm{H}^{-}$, nucleoside monophosphate [NMP $-\mathrm{H}]^{-}$, and their dehydration products $\left[\mathrm{NDP}-\mathrm{H}_{2} \mathrm{O}-\mathrm{H}\right]^{-}$and $\left[\mathrm{NMP}-\mathrm{H}_{2} \mathrm{O}-\right.$ $\mathrm{H}$ ] . At higher collision energy, an additional diagnostic fragment of [ribosyl(or deoxyribosyl)-5' $-\mathrm{P}_{2} \mathrm{O}_{5}-\mathrm{H}$ ] is produced by compounds with trans configuration. Several other nondiagnostic fragments are observed in tandem mass spectra of both cis and trans sugar nucleotides, the composition of which implies the occurrence of profound molecular rearrangements before or during the collision-activated dissociation of their deprotonated molecules.

Likewise, glycosyl esters of polyisoprenyl phosphates with cis and trans configuration of the phosphate and 2'-hydroxyl groups fragment in two different ways. Deprotonated molecules of compounds with cis configuration (as in $\beta$-D-mannopyranosyl-P-polyisoprenols and $\beta$-D-arabinofuranosyl-P-decaprenol) produce two abundant fragments, one of which is derived from the cleavage across the sugar ring and corresponds to [polyisoprenyl- $\left.\mathrm{PO}_{4}-\left(\mathrm{C}_{2} \mathrm{H}_{3} \mathrm{O}\right)\right]^{-}$; the second fragment is that of the [polyisoprenyl- $\left.\mathrm{HPO}_{4}\right]^{-}$ion. Orly the latter fragment is present in tandem mass spectra of the $[\mathrm{M}-\mathrm{H}]^{-}$ion of polyisoprenyl-P-sugars with trans configuration of the $\mathrm{C}-1^{\prime}$ and $\mathrm{C}-2^{\prime}$ oxygens (as in $\alpha$-D-mannopyranosyl-P-polyisoprenols and $\beta$-Dribofuranosyl-P-decaprenol). Accordingly, the ratio of the relative intensities of the [polyisoprenyl- $\mathrm{PO}_{4}{ }^{-}$ $\left.\left(\mathrm{C}_{2} \mathrm{H}_{3} \mathrm{O}\right)\right]^{-}$ion to the [polyisoprenyl- $\left.\mathrm{HPO}_{4}\right]^{-}$ion is close to 1 and 0.01 for compounds with cis and trans configuration, respectively.

Further studies on low collision energy-induced dissociation of chemically or enzymatically synthesized $\alpha$ and $\beta$ isomers of phosphorylated sugar derivatives that contain other kinds of monosaccharides, in conjunction with molecular modeling studies, will be necessary to better understand the collision-induced dissociation reaclions and to verify the general applicability of the FAB-MS/MS technique to the determination of the anomeric configuration of sugar nucleotides, polyisoprenyl-P-sugars, and sugar 1-phosphates. 


\section{Acknowledgments}

This work was supported by a grant (to B.A.W.) from the UNDP/World Bank/WHO Special Programme for Research and Training in Tropical Diseases (project 920454) and grant 9.4508 .92 (to E.d.H.) for collective research from the Fondation de la Recherche Scientifique et Médicale (FRSM), Belgium.

\section{References}

1. Hemming, F. W. In Glycolipids; Wiegandt, H., Ed.; Elsevier Science Publishers: Amsterdam, 1985; pp 261-305.

2. Kornfeld, R.; Kornfeld, S. Ann. Re?. Biochem. 1985, 54, $631-664$.

3. Bugg, T. D. M.; Brandish, P. E. FFMS Microbiol. Lett. 1994 $119,25 \overline{3}-262$.

4. Park, J. T.; Johnson, M. J. Biol. Chom. 1949, 179, 585-592.

5. Kochetkov, N. K.; Shibaev, V. N. Adt. Carbohytr. Chem. Biochem. 1973, 28, 307-399.

6. Gabriel, O. Methots Enzumol. 1982, 83, 332-353.

7. Shibaev, V. N. Ade. Corbohydr. Chem. Biochem. 1986, 44, $277-339$.

8. Okuda, S.; Murata, S.; Suzuki, N. Bioch'm. J. 1986, 239, $733-738$.

9. Franco, L.; Guida, L.; Zocchi, L.; Silvestro, L.; Benatti, U.; De Flora, A. Biochem. Biophys. Re's. Commun. 1993, 190, 1143-1148.

10. Handwerger, S.; Pucci, M. J.; Volk, K. J.; Liu, J.; Lee, M. S. J. Bacteriol. 1994, 176, 260-264.

11. Schneider, P.; McConville, M. J.; Ferguson, M. A. J. J. Biol. Chem. 1994, 269, 18332-18337.

12. Hartmann, E.; König, H. Biol. Chem. Hoppe Siyler 1991, 372 , 971-974.

13. Badet, J.; Jeanloz, R. W. Carbohydr. Res. 1988, 178, 49-65.

14. Wolucka, B. A.; McNeil, M. R.; de Hoffmann, E.; Chojnacki, T.; Brennan, P. J. I. Biol. Chem. 1994, 269, 23328-23335.

15. Schwartz, R. T.; Datema, R. Adt. Carbohydr. Chem. Biodem. 1982, 40, 287-379.

16. Lezica, R. P.; Daleo, G. R. Adt. Carbohydr. Chom. Biochem. 1986, 44, 341-385.

17. Kean, E. L. J. Biol. Chom. 1985, 260, 12561-12571.

18. Rush, J. S.; Shelling, J. G.; Zingg, N. S.; Ray, P. H.; Waechter, C. J. J. Biol. Chom. 1993, 268, 1311013117.
19. DeLuca, A. W.; Rush, J. S.; Lehrman, M. A.; Waechter, C. J. Glycobiolugy 1994, 4, 909916.

20. Dotson, S. B.; Rush, J. S.; Ricketts, A. D.; Waechter, C. J. Arch. Biochen. Biophys 1995, 316, 773-779.

21. Kean, E. L.; Rush, J. S.; Waechter, C. J. Biochinistry 1994, 33 , $10508 \cdots 10512$.

22. Legler, G. Carbohytr. Re's. 1993, 250, vii xx.

23. Herscovics, A.; Warren, C. D.; Jeanloz, R. W. J. Biol. Chem. $1975,250), 8079-8084$.

24. Murazumi, N.; Yamamori, S.; Araki, Y.; [to, E. J. Biol. Chem. 1979, 254, $11791-11793$.

25. Weng, Q.-M.; Hammargren, W. M.; Slowikowski, D.; Schram, K. H.; Borysko, K. Z.; Wotring, L. L.; Townsend, L. B. Anal. Biochem. 1989, 178, 102-106.

26. Crain, P. F. Masis Spectrome. Reve. 1990, 9, 505-551.

27. Phillips, D. R.; McCloskey, J. A. Int. I. Mass Spectrom. Ion Processes 1993, 128, 61-82.

28. Ii, T.; Okuda, S.; Hirano, T.; Tsujimoto, K.; Ohashi, M. Oro. Mass Spectrom. 1993, 28, 127-131.

29. Wolucka, B. A.; de Hollmann, E. Acta Biochim. Pol. 1994, 41, 345-349.

30. Brakta, M.; Chaguir, B.; Sinou, D.; Banoub, J.; Becchi, M. Org. Mass Spectrom. 1992, 27, 331 339.

31. Ii, T.; Okuda, S.; Hirano, T.; Tsujimoto, K.; Ohashi, M. Org. Mass Spectrom. 1993, 28, 789-794.

32. Banoub, J. H.; Mackenzie, G.; Descotes, G.; Humble, R. W.; Shaw, G.; Rechi, M.; Fraisse, D. Biomerd. Fntiron. Mass Spectrom. 1990, 19, 97-99.

33. Banoub, J. H.; Ewing, D. F.; Humble, R. W.; Mackenzie, G.; Becchi, M.; Fraisse, D.; Descotes, G.; Shaw, G. Nucleosides Nuclotides 1991, 10, 657-658.

34. Dell, A.; Reason, A. J.; Khoo, K.-H.; Panico, M.; McDowell, R. A.; Morris, H. R. Methods Enzymol. 1994, 230, 108-132.

35. Wolucka, B. A.; de Hoffmann, E. I. Am. Soc. Mass Spectrom. $1995,6,516-520$.

36. Wolucka, B. A.; de Hoffmann, E. I. Biol. Chem. 1995, 270 , 20151-20155.

37. Winkler, F. J.; Splitter, J. S. In Applications of Mass Spectronetry to Orgmic Sterochemistry; Splitter, J. S.; Turecek, F., Eds.; VCH Publishers: New York, 1994; pp 461-467.

38. Berjeaud, J.-M.; Couderc, F.; Promé, J.-C. Org. Mass Spectrom. $1993,28,455-458$. 